\author{
SANDIA REPORT \\ SAND2006-1902 \\ Unlimited Release \\ Printed June 2006
}

\title{
Thermally-Related Safety Issues Associated with Thermal Batteries
}

\author{
Ronald A. Guidotti
}

Prepared by

Sandia National Laboratories

Albuquerque, New Mexico 87185 and Livermore, California 94550

Sandia is a multiprogram laboratory operated by Sandia Corporation, a Lockheed Martin Company, for the United States Department of Energy's

National Nuclear Security Administration under Contract DE-AC04-94AL85000.

Approved for public release; further dissemination unlimited. 
Issued by Sandia National Laboratories, operated for the United States Department of Energy by Sandia Corporation.

NOTICE: This report was prepared as an account of work sponsored by an agency of the United States Government. Neither the United States Government, nor any agency thereof, nor any of their employees, nor any of their contractors, subcontractors, or their employees, make any warranty, express or implied, or assume any legal liability or responsibility for the accuracy, completeness, or usefulness of any information, apparatus, product, or process disclosed, or represent that its use would not infringe privately owned rights. Reference herein to any specific commercial product, process, or service by trade name, trademark, manufacturer, or otherwise, does not necessarily constitute or imply its endorsement, recommendation, or favoring by the United States Government, any agency thereof, or any of their contractors or subcontractors. The views and opinions expressed herein do not necessarily state or reflect those of the United States Government, any agency thereof, or any of their contractors.

Printed in the United States of America. This report has been reproduced directly from the best available copy.

Available to DOE and DOE contractors from

U.S. Department of Energy

Office of Scientific and Technical Information

P.O. Box 62

Oak Ridge, TN 37831

Telephone: $\quad$ (865) 576-8401

Facsimile: $\quad$ (865) 576-5728

E-Mail: $\quad$ reports@adonis.osti.gov

Online ordering: http://www.osti.gov/bridge

Available to the public from

U.S. Department of Commerce

National Technical Information Service

5285 Port Royal Rd.

Springfield, VA 22161

Telephone: $\quad$ (800) 553-6847

Facsimile: (703) 605-6900

E-Mail: $\quad$ orders@ntis.fedworld.gov

Online order: $\quad$ http://www.ntis.gov/help/ordermethods.asp?loc=7-4-0\#online

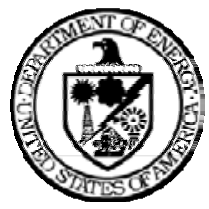


SAND2006-1902

Unlimited Release

Printed June 2006

\title{
Thermally-Related Safety Issues Associated with Thermal Batteries
}

\author{
Ronald A. Guidotti ${ }^{1}$ \\ Power Sources Development Dept. \\ Sandia National Laboratories \\ P.O. Box 5800 \\ Albuquerque, NM 87185-0614
}

\begin{abstract}
Thermal batteries can experience thermal runaway under certain usage conditions. This can lead to safety issues for personnel and cause damage to associated test equipment if the battery thermally self destructs. This report discusses a number of thermal and design related issues that can lead to catastrophic destruction of thermal batteries under certain conditions. Contributing factors are identified and mitigating actions are presented to minimize or prevent undesirable thermal runaway.
\end{abstract}

\footnotetext{
${ }^{1}$ Present address: Sierra Nevada Consulting, 1536 W. High Pointe Ct., Minden, NV 89432; e-mail: RonGuidotti@SierraNevadaConsulting.com
} 
This page intentionally left blank. 


\section{Contents}

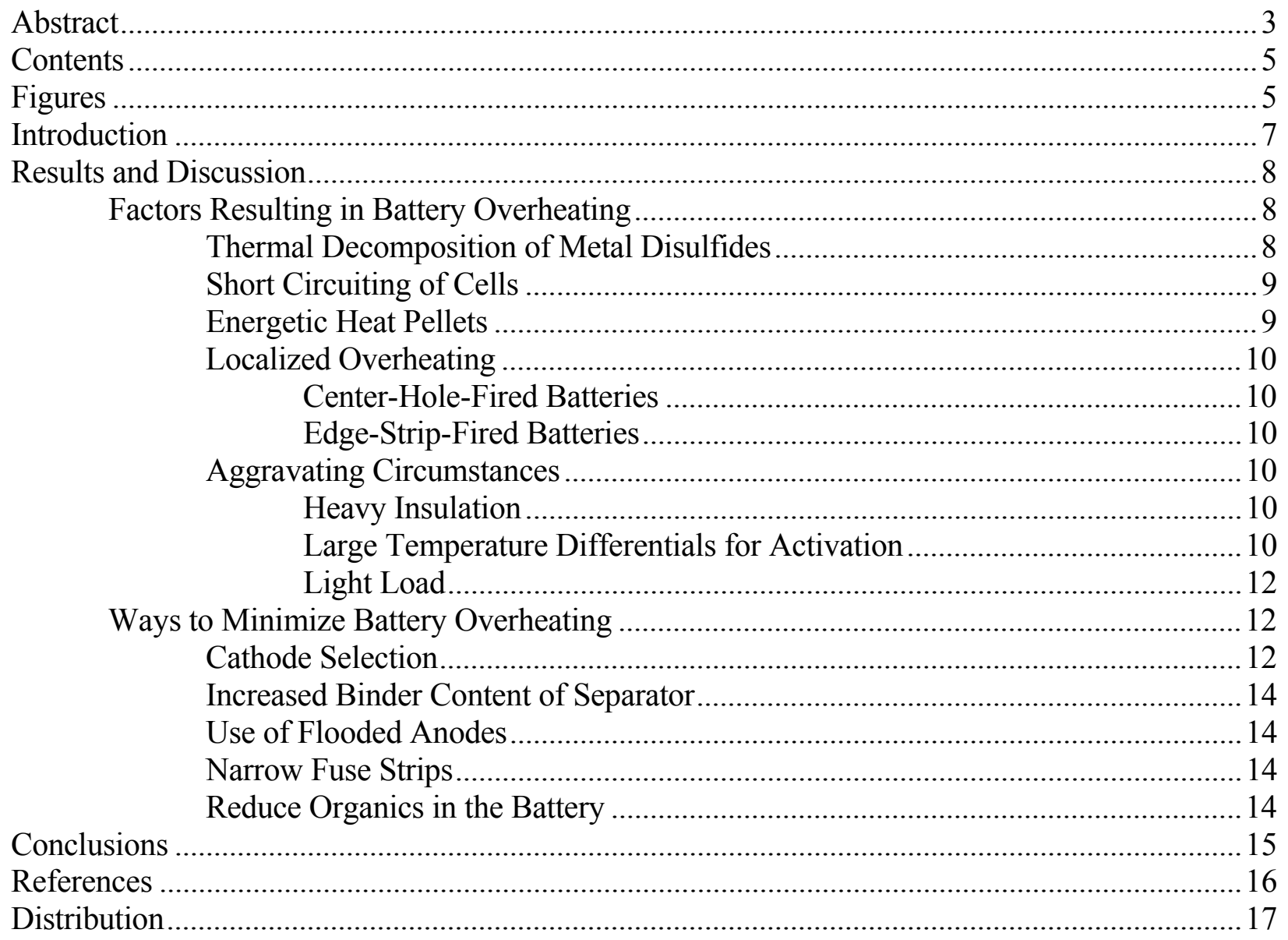

\section{Figures}

Figure 1. Schematic Representation of a Typical Thermal Cell ................................................... 8

Figure 2. Schematic Representation of Batteries Built with Wide and Narrow Fuse Strips........11

Figure 3. Schematic Representation of Overheating Scenario for Edge-Strip-Fired $\mathrm{Li}(\mathrm{Si}) / \mathrm{FeS}_{2}$ Thermal Battery ….......................................................................11

Figure 4. Pulse-Voltage Response of a $25-\mathrm{Cell} \mathrm{Li}(\mathrm{Si}) / \mathrm{FeS}_{2}$ Thermal Battery under ThermalRunaway Conditions ..............................................................................................13

Figure 5. Stack Temperature of a $25-\mathrm{Cell} \mathrm{Li}(\mathrm{Si}) / \mathrm{FeS}_{2}$ Thermal Battery under ThermalRunaway Conditions. 
This page intentionally left blank. 


\section{Thermally-Related Safety Issues Associated with Thermal Batteries}

\section{INTRODUCTION}

Safety issues relating to the testing and use of thermal batteries have always been a consideration in design. Potential problems can occur if the battery overheats. Heat can be generated by direct chemical reaction between the electroactive components, such as the $\mathrm{Li}(\mathrm{Si})$ anode and the $\mathrm{FeS}_{2}$ cathode. This can occur if the separator in the battery is physically breached. Another type of exothermic reaction can occur when epoxy encapsulation is used for the header assembly. If heat generation becomes great enough, pyrolysis reactions can occur, which generate large amounts of water and gases. The water, in turn, can react with the anode, generating even more heat. This additional heat increases the exothermic reaction rates even further until the battery spirals into a thermal runaway condition. As the pressure within the battery increases, the battery case may bulge and, if stresses become great enough, failure of the glass-to-metal seals in the header can result. Under worst-case conditions, the pressure can increase so rapidly that battery case can melt and vent violently, spewing molten materials into the immediate environment.

There are obvious hazards to personnel in the vicinity of the testing. If the battery vents, toxic, noxious, and corrosive gases will be evolved, such as $\mathrm{SO}_{2}$, resulting from the oxidation of the $\mathrm{FeS}_{2}$ cathode (eqn. 1).

$$
2 \mathrm{FeS}_{2(\mathrm{~s})}+5.5 \mathrm{O}_{2(\mathrm{~g})}+----->\quad \mathrm{Fe}_{2} \mathrm{O}_{3(\mathrm{~s})}+4 \mathrm{SO}_{2}(\mathrm{~g})
$$

Pyrolysis of the epoxy encapsulant in the header assembly will generate carcinogenic and toxic organic vapors. ${ }^{1}$ Reactions of the $\mathrm{Li}(\mathrm{Si})$ anode with ambient oxygen and moisture are also very exothermic and will generate $\mathrm{Li}_{2} \mathrm{O}$ fumes, which are very irritating to the respiratory system (eqn. 2 and 3).

$$
\begin{aligned}
& 2 \mathrm{Li}(\mathrm{Si})+2.5 \mathrm{O}_{2(\mathrm{~g})}------>\quad \mathrm{Li}_{2} \mathrm{O}_{(\mathrm{s})}+2 \mathrm{SiO}_{2(\mathrm{~s})} \\
& 2 \mathrm{Li}(\mathrm{Si})+5 \mathrm{H}_{2} \mathrm{O}_{(\mathrm{g})}------>\quad \mathrm{Li}_{2} \mathrm{O}_{(\mathrm{s})}+2 \mathrm{SiO}_{2(\mathrm{~s})}+5 \mathrm{H}_{2}(\mathrm{~g})
\end{aligned}
$$

Similar reactions occur with $\mathrm{Li}(\mathrm{Al})$ and immobilized-Li anodes.

Hot, sometimes-molten battery debris and shrapnel also pose risks to nearby personnel. That is why it is mandatory that battery testing be conducted in a safety enclosure with provision for capture of debris and venting of any offgases to a hood or scrubber system. This will also prevent destruction or damage of any expensive nearby test equipment.

This report summarizes a number of mechanisms that can lead to thermal runaway conditions and ways to mitigate them. 


\section{RESULTS AND DISCUSSION}

A schematic diagram of a typical thermal cell is shown in Figure 1. A number of electrolytes can be used in thermal batteries, but these will not generally impact the runaway mechanisms.

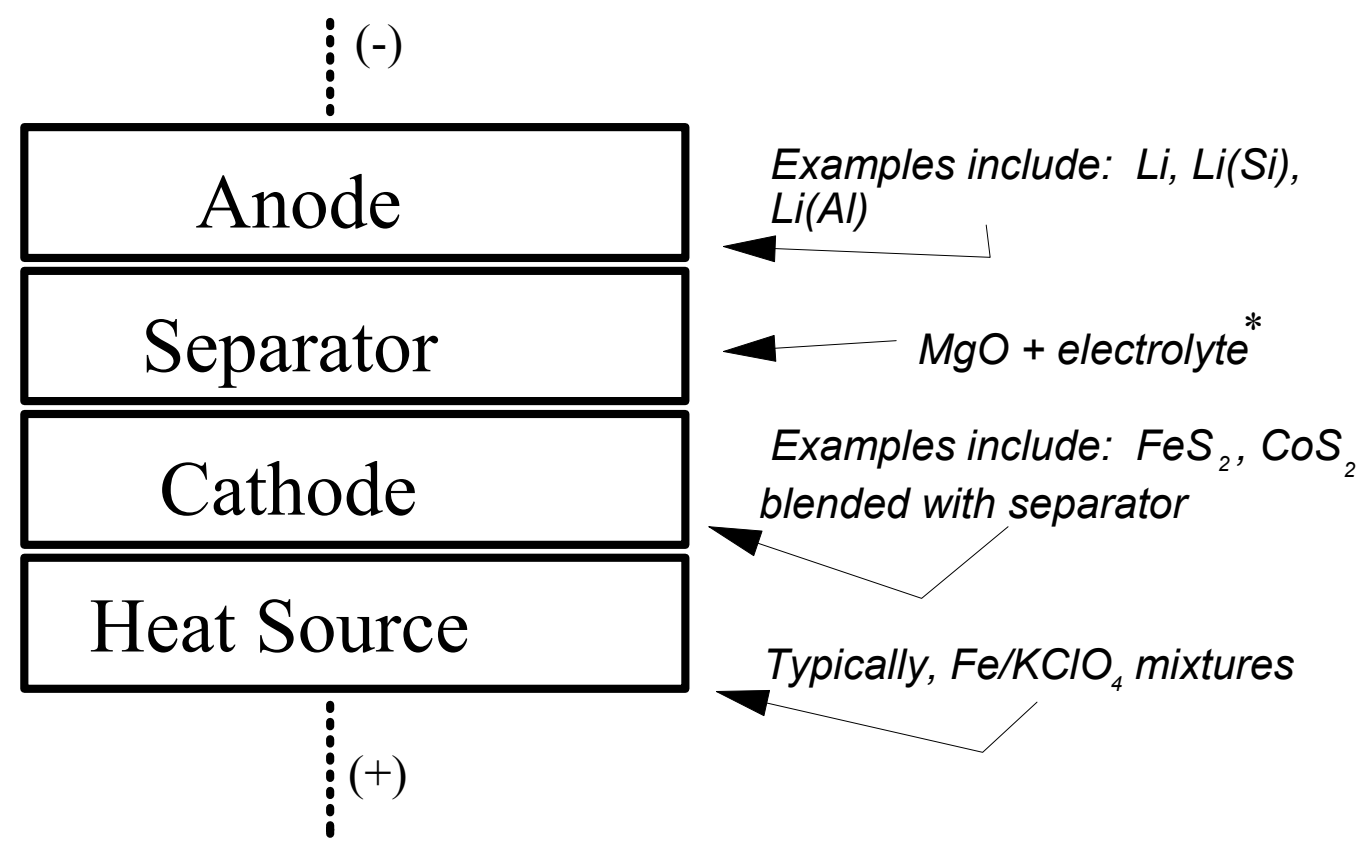

* Electrolytes include: LiCl-KCl,LiCl-LiBr-LiF, LiBr-KBr-LiF, and LiBr-KBr-LiCl

Figure 1. Schematic Representation of a Typical Thermal Cell.

\section{Factors Resulting in Battery Overheating}

\section{Thermal Decomposition of Metal Disulfides}

The primary mechanism for thermal runaway of $\mathrm{Li}(\mathrm{Si}) / \mathrm{FeS}_{2}$ and $\mathrm{Li}(\mathrm{Si}) / \mathrm{CoS}_{2}$ thermal batteries involves thermal decomposition of the cathode. Excessive heat input to the thermal battery during activation can initiate the thermal decomposition of the metal disulfide cathode. In the case of pyrite, the onset of thermal decomposition is $\sim 550^{\circ} \mathrm{C}$, while that for $\mathrm{CoS}_{2}$ is $\sim 650^{\circ} \mathrm{C}$. If these temperatures are maintained for more than several minutes, substantial decomposition can take place:

$$
\mathrm{MS}_{2(\mathrm{~g})}------>\mathrm{MS}_{(\mathrm{s})}+0.5 \mathrm{~S}_{2(\mathrm{~g})}
$$

The released sulfur vapors then will react very exothermically with both the $\mathrm{Li}(\mathrm{Si})$ anode and to a lesser degree with the hot, excess Fe in the heat pellet and with the stainless steel current collectors and Ni leads. 


$$
\begin{aligned}
& 2 \mathrm{Li}(\mathrm{Si})+2.5 \mathrm{~S}_{2(\mathrm{~g})}------>\quad \mathrm{Li}_{2} \mathrm{~S}_{(\mathrm{s})}+2 \mathrm{SiS}_{2(\mathrm{~s})} \\
& \mathrm{Fe}+0.5 \mathrm{~S}_{2(\mathrm{~g})} \quad----->\quad \mathrm{FeS}_{(\mathrm{s})} \\
& \mathrm{Ni}+0.5 \mathrm{~S}_{2(\mathrm{~g})} \quad----->\mathrm{NiS}_{(\mathrm{s})}
\end{aligned}
$$

The heat generated by these reactions raises the temperature of the battery stack even more, resulting in even more decomposition of metal disulfide and the formation of more fugitive sulfur. Ultimately, the battery goes into thermal runaway and destroys itself.

One reason for initial overheating is an activation temperature much higher than that for which the battery was designed. Another reason can be the wrong heat-powder composition or wrong weight of heat pellet may have been used. All of these will raise the battery stack temperature above the design level.

\section{Short Circuiting of Cells}

Another means for causing battery overheating relates to a short across one or more cells in a battery stack. This can result from particles of anode or cathode bridging the separator of a cell. This can occur from pellet edges chipping during wrapping of the battery stack, especially when the separators are very thin ( $\sim 0.010$ " or less). Since both the cathode and anode materials are electronically conducting, any bridging that might occur will result in shorting of cells after battery activation. This effect will be much quicker, in terms of stack overheating, than the thermal decomposition of the cathode materials.

The relative diameters of the component pellets in a cell are important to prevent or minimize possible cell shorting. The separator pellets are typically slightly larger in diameter the anode and cathode pellets for that reason. The use of thin anode and cathode pellets increases the risk of chipping and possible shorting due to reduced structural strength.

Even with the proper dimensional control of the cell pellets, there is a possibility that collapse of the separator can occur in batteries under some conditions. This is most likely when there is overheating of the battery stack. Under those conditions, the electrolyte in the separator becomes more fluid and can leak into the insulating wrap surrounding the battery. The separator can then collapse or be reduced in thickness sufficiently to allow direct physical contact between the anode and cathode. Without a physical barrier present, direct chemical reaction can then occur, leading to rapid exothermic reactions, such as eqn. 8:

$$
4 \mathrm{Li}(\mathrm{Si})+\mathrm{FeS}_{2}---->2 \mathrm{Li}_{2} \mathrm{~S}+\mathrm{Fe}+4 \mathrm{Si}
$$

The heat generated by the reaction of the $\mathrm{Li}$ amounts to $175 \mathrm{kcal} / \mathrm{mole}$ of $\mathrm{FeS}_{2}$. 


\section{Energetic Heat Pellets}

The burning of $\mathrm{Fe} / \mathrm{KClO}_{4}$ heat pellets produces a very high temperature that can impact the adjacent cathode pellet in a cell. Temperatures can easily exceed $1,100^{\circ} \mathrm{C}$ in a heat pellet burning alone. ${ }^{2}$ A current collector or graphite-paper substrate placed between the cathode and heat pellet serves to temper the thermal impulse generated by the burning heat pellet. As the calorific output of the heat pellet is progressively increased (i.e., higher levels of $\mathrm{KClO}_{4}$ ), the burn rate increases almost exponentially along with the peak burn temperature. ${ }^{2}$ This increases the risk of initiating possible overheating, especially for a battery activated under hot conditions.

\section{Localized Overheating}

Center-Hole-Fired Batteries - Localized overheating is a manifestation on a reduced scale of the cathode thermal decomposition described above. In the case of a center-hole-fired battery, the igniter fires down the center hole to ignite the heat pellets that protrude into the center hole. If an igniter is used that is overpowered for the length of the battery stack, the additional heat could initiate localized thermal decomposition at the edge of the cathode pellets near the center hole.

Edge-Strip-Fired Batteries - There is also a possibility of localized overheating in the case of a battery ignited by a fuse strip along the edge of the battery stack. This can occur if the fuse strip is too wide, as shown in Figure 2, which shows 6-mm-wide and 3$\mathrm{mm}$-wide fuse strips being used. Localized overheating at the edge of pellets can occur with the wide fuse trains, since there is more heat input to the active electrodes. The risk of this is increased with the use of thin $(\leq 0.25$-mm-thick $)$ anodes and cathodes, since they have a lower thermal mass than thicker electrodes. This is illustrated schematically in Figure 3 for the case of localized overheating of the disulfide cathode.

Thicker cathode cells have more mass that can dissipate the heat generated by the burning heat-paper strip. The tendency for localized overheating is reduced with the use of the more-thermally stable $\mathrm{CoS}_{2}$ cathode vs. the conventional $\mathrm{FeS}_{2}$ cathode. Thermal decomposition of the pyrite can occur at the pellet edge, releasing sulfur vapors that will then react with the adjacent anode or heat pellets, generating even more localized heating. In severe circumstances, this can eventually lead to a thermal runaway.

\section{Aggravating Circumstances}

Heavy Insulation - The possibility for thermal batteries to overheat is aggravated by certain conditions. When batteries are heavily insulated, such as for long-life $(>1 \mathrm{~h})$ applications, the rate of heat loss will be dramatically reduced. Min- $\mathrm{K}^{\circledR}$ or Microtherm ${ }^{\circledR}$ composite insulations are generally used for those applications. The same conditions would also exist if a vacuum multifoil container or aerogel insulation were used.

Large Temperature Differentials for Activation - A very large temperature extreme for activation conditions increases the risk for overheating. The battery must function as designed at both the cold extreme as well as the hot extreme. Temperature differentials of $130^{\circ} \mathrm{C}$ or more can result. A battery activated under the hot extreme will be at greatest risk of overheating. 


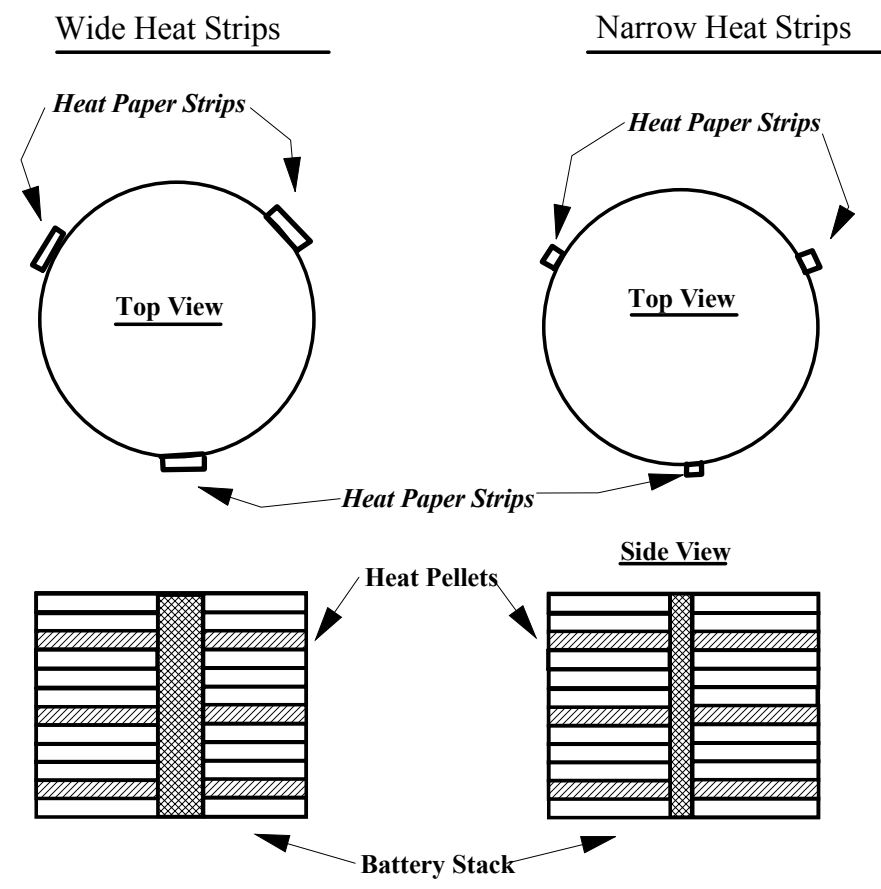

Figure 2. Schematic Representation of Batteries Built with Wide and Narrow Fuse Strips.

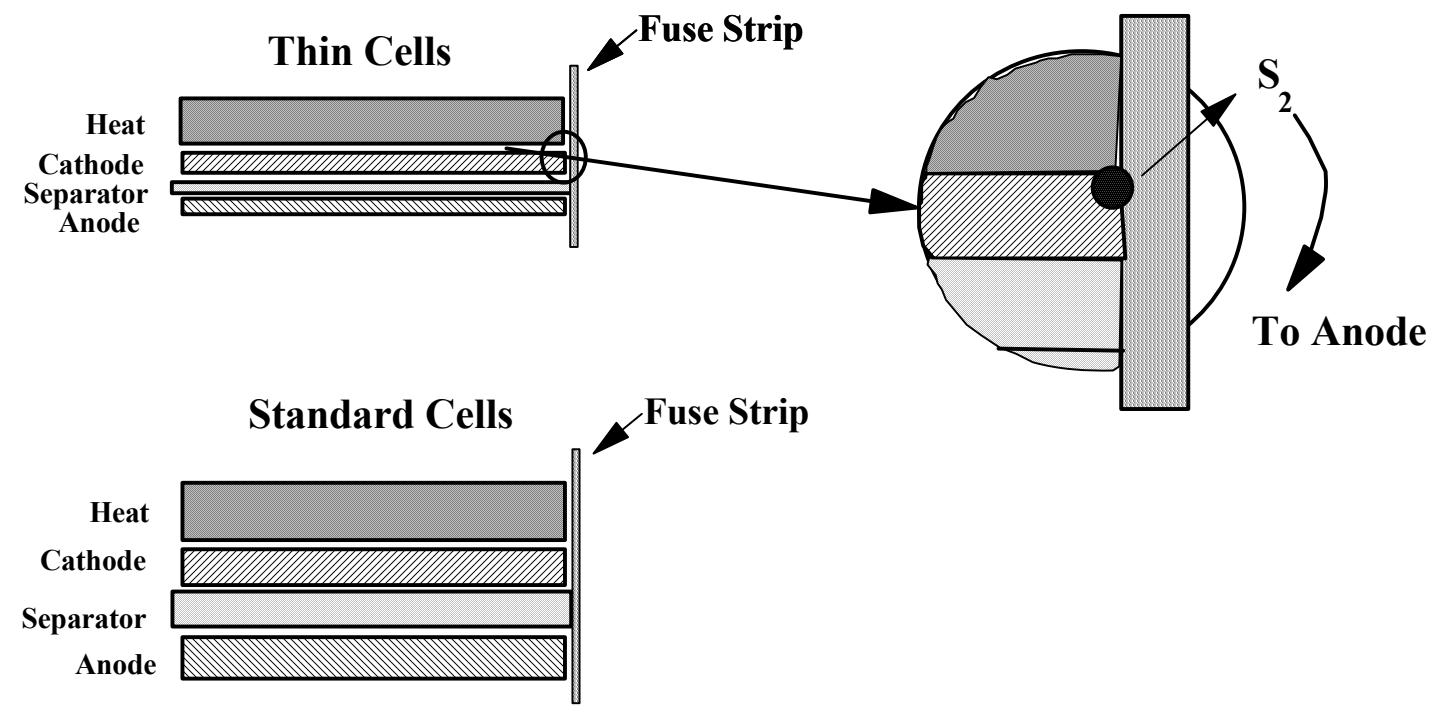

$$
2 \mathrm{Li}+\mathrm{Si}+1.5 \mathrm{~S}_{2}--->\quad \mathrm{LiS}_{2}+\mathrm{SiS}_{2}+145 \mathrm{kcal}
$$

Figure 3. Schematic Representation of Overheating Scenario for Edge-Strip-Fired $\mathrm{Li}(\mathrm{Si}) / \mathrm{FeS}_{2}$ Thermal Battery. 
Light Load - The load that a battery will experience can impact the risk of overheating. Under a heavy load, any sulfur that is released from overheating of the disulfide cathode can be electrochemically consumed before it has a chance to escape and chemically react with the anode or heat pellets.

$$
0.5 \mathrm{~S}_{2(\mathrm{~g})}+2 \mathrm{e}^{-} \quad----->\mathrm{S}^{-2}
$$

However, under a light load (e.g., $<25 \mathrm{~mA} / \mathrm{cm}^{2}$ ), the rate of sulfur generation may be greater than the electrochemical rate of consumption, leading to a net loss of sulfur from the cathode, initiating a thermal runaway.

There is also the possibility, although relatively low, of localized overheating by wide fuse strips of the Li-alloy anode pellets caused by reaction with the oxygen that is sealed in the battery after it is welded shut. This scenario is only relevant for relatively recently sealed batteries, where the residual internal battery overgas contains substantial oxygen. After standing for a month or more, however, almost all of the oxygen sealed into a battery is gettered by the anodes, as illustrated by eqn. 2 for $\mathrm{Li}(\mathrm{Si})$. In addition, any residual moisture is desorbed and also reacts with the anode to generate a partial pressure of hydrogen, as shown by eqn. 3 for $\mathrm{Li}(\mathrm{Si}){ }^{3}$ An overheated anode pellet can initiate overheating of the adjacent cathode pellet, since they are in good thermal contact.

The voltage of a 25 -cell $\mathrm{Li}(\mathrm{Si}) / \mathrm{LiCl}-\mathrm{KCl} / \mathrm{FeS}_{2}$ thermal battery under typical runaway conditions is illustrated in Figure 4; the corresponding temperature of the battery stack is shown in Figure 5. The battery voltage dropped off rapidly after $80 \mathrm{~s}$, gradually falling to nearly zero after $250 \mathrm{~s}$. The temperature trace showed a temporary loss of contact after $80 \mathrm{~s}$, with a subsequent rapid rise to almost $1,200^{\circ} \mathrm{C}$ after only $220 \mathrm{~s}$.

\section{Ways to Minimize Battery Overheating}

\section{Cathode Selection}

In some applications, there is a delicate balance between achieving satisfactory battery performance at the temperature extremes of the required thermal environment. The greater the activation-temperature range, the more difficult it is to meet all of the battery performance requirements with the conventional $\mathrm{Li}(\mathrm{Si}) / \mathrm{FeS}_{2}$ system. Under those conditions, it may be advisable to consider the use of a cathode material that is more thermally stable, such as $\mathrm{CoS}_{2}$. This material does not thermally decompose until $\sim 650^{\circ} \mathrm{C}$, which is $\sim 100^{\circ} \mathrm{C}$ higher than the decomposition temperature for $\mathrm{FeS}_{2}$. This material also has higher power capabilities, since it is a better electronic conductor than pyrite. It also should be considered when required battery lifetimes are extremely long, i.e., one hour or more. $\mathrm{CoS}_{2}$ also has reduced solubility in molten electrolytes, which minimizes the tendency for self discharge caused by chemical reaction of the dissolved sulfide species with the $\mathrm{Li}(\mathrm{Si})$ anode. The downside to the use of $\mathrm{CoS}_{2}$ is that it is much more expensive than pyrite and must be chemically synthesized, while pyrite is a natural is a readily available natural mineral. 


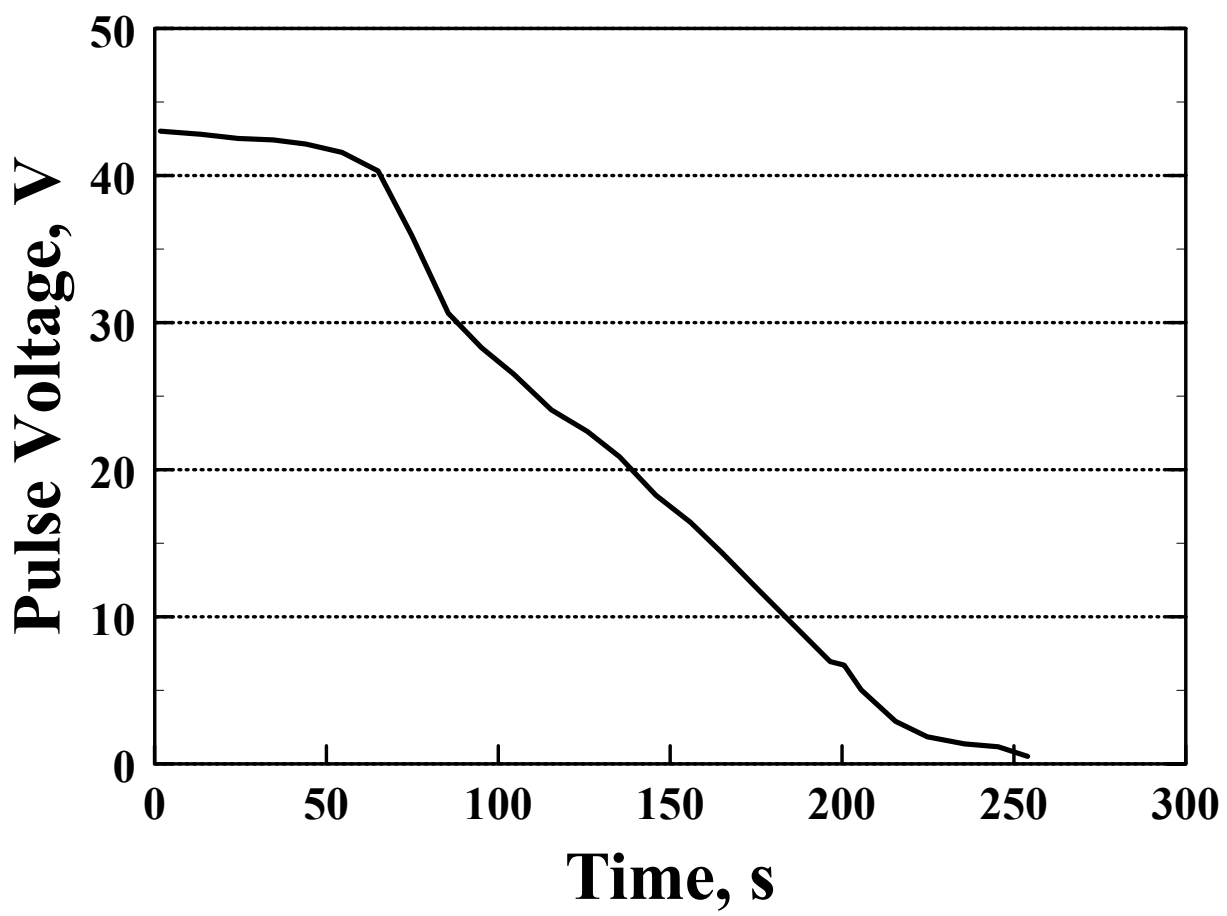

Figure 4. Pulse-Voltage Response of a $25-\mathrm{Cell} \mathrm{Li}(\mathrm{Si}) / \mathrm{FeS}_{2}$ Thermal Battery under Thermal-Runaway Conditions.

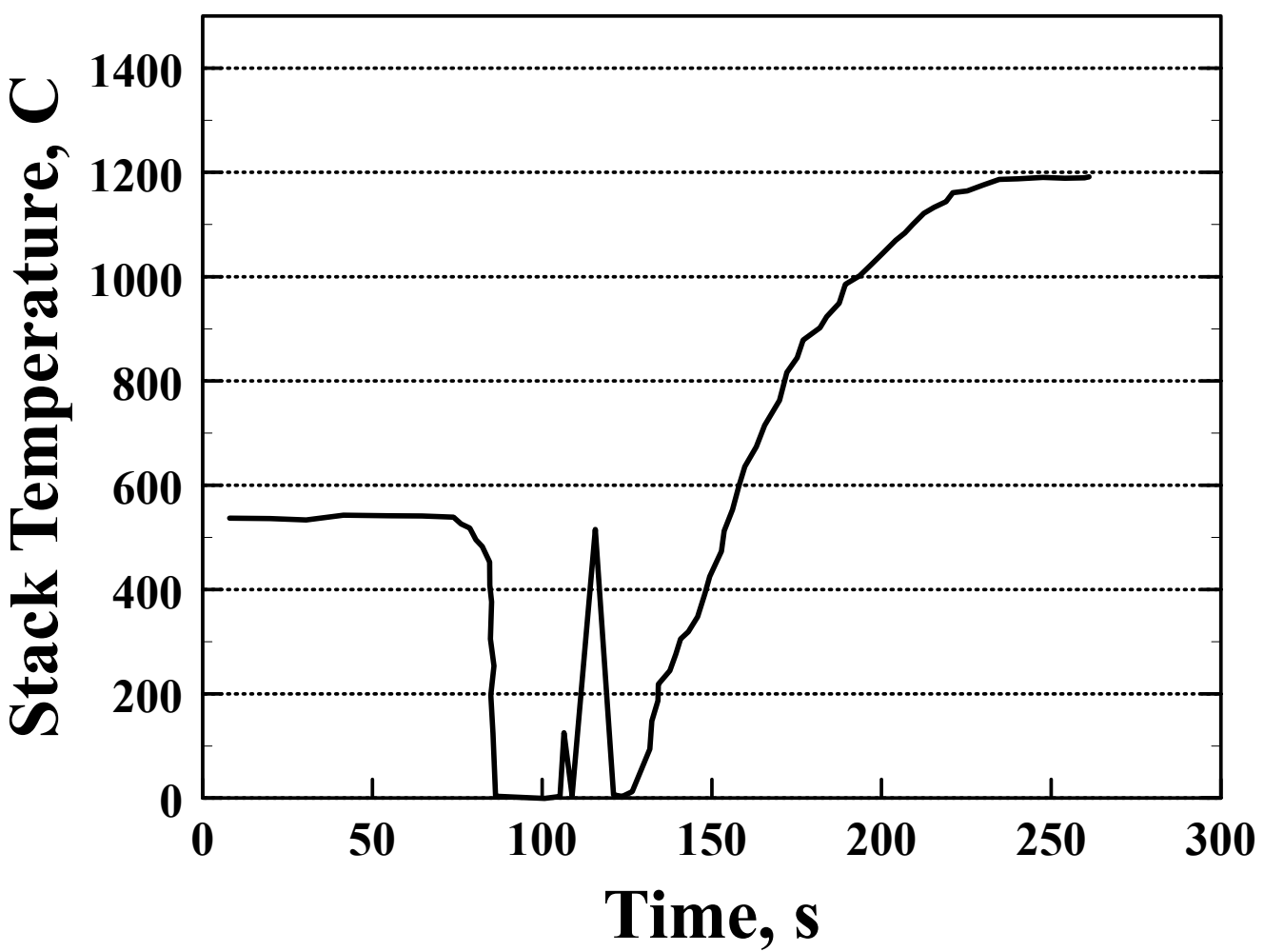

Figure 5. Stack Temperature of a $25-\mathrm{Cell} \mathrm{Li}(\mathrm{Si}) / \mathrm{FeS}_{2}$ Thermal Battery under Thermal-Runaway Conditions. 
Other cathodes that may have promise have been under study at Sandia over the last decade. $^{4,5}$ Many of these are oxides which have a higher voltage vs. Li(Si) than does $\mathrm{FeS}_{2}$. However, in some cases, these voltages are higher than the thermodynamic decomposition voltages of a number of the halides used in conventional thermal-battery electrolytes (i.e., $\mathrm{LiBr}$ ), which requires the use of alternative electrolytes. One category of such electrolytes involves molten nitrates. ${ }^{6-8}$ More work is needed, however, to overcome some of the new problems that the use of such electrolytes can cause.

\section{Increased Binder Content of Separator}

Increasing the $\mathrm{MgO}$ binder content of the separator can assist in reducing the tendency for overheating by decreasing electrolyte leakage into the battery insulating wrap and adjacent anode and cathode. This, in turn, minimizes the tendency for parasitic shunting currents and the likelihood for breaching of the separator, which can occur from separator collapse under overheated conditions. Unfortunately, the higher binder content will increase the overall impedance of the battery, so some tradeoffs will be necessary.

\section{Use of Flooded Anodes}

Incorporation of electrolyte into the anode (i.e., a flooded anode) helps to reduce the thermal impulse that the anode will see upon battery activation as a consequence of its thermal buffering during melting of the electrolyte. A thermal sink is provided by the heat of fusion of the electrolyte that would not be present in its absence. Having electrolyte present in the anode will reduce the tendency of electrolyte migration into the anode from the separator during discharge. This electrolyte migration can result in electrolyte starvation with an accompanied rise in separator impedance. The end result is that an improvement in the electrochemical performance can be expected, as all parts of the anode will be made more readily accessible for discharge due to the presence of electrolyte. The presence of electrolyte facilitates ionic transport in the anode pellet. In addition, flooded anodes are more readily fabricated and require much less forming pressure relative to an unflooded anode.

\section{Narrow Fuse Strips}

Typically, three fuse (heat-paper) strips are used $120^{\circ}$ apart for edge-strip-fired thermal batteries. This approach increases the reliability and uniformity of ignition. If the fuse strips are too wide, however, there is the increased risk of localized overheating that can initiate a thermal runaway. Therefore, it is recommended that the fuse strips not be more than 3-4 mm wide. The narrower heat strip reduces the heat input at the edge of the pellets in the battery stack. This, in turn, minimizes the chance of overheating of the cathode pellets and exothermic oxidation of the anode. However, if the fuse strips are made too narrow, there is increased risk of breakage during battery wrapping, which could interfere with reliable ignition.

\section{Reduced Organics in the Battery}

The presence of organics adjacent to the thermal-battery stack can lead to unwanted pyrolysis if the battery stack should overheat. Such organics are associated with the adhesive in the glass tape strip used to hold the wrap in place. This contribution is not significant, however, when compared to that from the epoxy encapsulation in many 
headers. The amount of organic in the glass tape is not significant since only a small piece is used. However, there is a substantial source of reactive decomposition products (e.g., water) associated with the epoxy encapsulant should it begin to pyrolyze in an overheated battery. The use of a so-called "built-up" header is a logical alternative to the use of epoxy encapsulant in the header. This involves the use of insulating discs (e.g., Fiberfrax $^{\circledR}$, Min- $^{\circledR}$, or Microtherm ${ }^{\circledR}$ ) over the pins of the header to protect them and to provide a base on which the battery stack can be constructed. This approach is also recommended for any long-life battery where the battery will be at temperature for a considerable period of time $(\geq 1 \mathrm{~h})$. Where the use of a built-up header is not possible, adequate insulation between the end of the battery stack and the encapsulated header should be provided.

\section{Conclusions}

A number of factors can lead to the overheating of a Li-alloy/metal disulfide thermal batteries during discharge. These include thermal decomposition of the metal disulfide cathode (e.g., $\mathrm{FeS}_{2}$ ) that can generate fugitive sulfur vapors that react with the Li-alloy anode. Short circuiting of individual cells can also lead to overheating especially if collapse of the separator occurs and direct contact of the anode and cathode takes place. Overly energetic pyrotechnics (heat pellets) can initiate overheating under certain conditions. Equally important is localized overheating caused by he use of too-wide a fuse train for edge-fired batteries. This can result in localized thermal decomposition of the disulfide cathode, generating sulfur vapor that will react with the anode, heat pellets, current collectors, and leads. This can also lead to exothermic oxidation of the anode with any residual oxygen sealed in the battery. All of these conditions can lead to a thermal runaway where the battery destroys itself. Venting, rupture, and melting of the battery case can occur, possibly releasing molten materials and toxic gases in the area near the battery. This poses personnel and environmental concerns. Batteries that are heavily insulated will aggravate any overheating conditions, as will large temperature differentials between the hot and cold activation extremes. Discharge under a light load will also aggravate any tendency to overheat, as any locally generated sulfur will not be electrochemically consumed rapidly enough to prevent undesirable chemical reactions with battery components.

The tendency for battery overheating can be minimized by the use of more-thermallystable cathodes, increased binder content of the separator, the use of flooded anodes, the use of narrower fuse strips for ignition, and the reduction of organics in the batteryespecially epoxy encapsulation. Each of these choices will involve some tradeoff in performance but will decrease the likelihood of thermal battery overheating under aggravating discharge conditions. 


\section{References}

1. R. A. Guidotti, S. M. Thornberg, and B. Campbell-Domme, "Pyrolysis of Epoxies Used for Thermal-Battery Headers," SAND95-1312 (August 1995).

2. Ronald A. Guidotti, Frederick W. Reinhardt, and Judy Odinek, "Characterization of $\mathrm{Fe} / \mathrm{KClO}_{4}$ Heat Powders for Thermal Batteries," Proc. $29^{\text {th }}$ Intern. Pyrotechnics Seminar, 847 (2002).

3. R. A. Guidotti and F. W. Reinhardt, "Gas-Pressure Studies with $\mathrm{Li}(\mathrm{Si}) / \mathrm{FeS}_{2}$ Thermal Batteries," Proc. 35th Intern. Power Sources Symp., 206 (1992).

4. Ronald A. Guidotti and Frederick W. Reinhardt, "Characterization of High-Voltage Cathodes in CsBr-LiBr-KBr Eutectic Electrolyte," Proc. $39^{\text {th }}$ Power Sources Conf., 470 (2000).

5. Ronald A. Guidotti and Frederick W. Reinhardt, "Screening Study of Mixed TransitionMetal Oxides for Use as Cathodes in Thermal Batteries," Proc. $37^{\text {th }}$ Power Sources Conf., 251 (1996).

6. Ronald A. Guidotti and Frederick W. Reinhardt, "Evaluation of the $\mathrm{Li}(\mathrm{Al}) / \mathrm{MnO}_{2}$ Couple in $\mathrm{LiNO}_{3}-\mathrm{KNO}_{3}$ Eutectic Electrolyte for Borehole Applications," Proc. $41^{\text {st }}$ Power Sources Conf., 141 (2004).

7. Ronald A. Guidotti and Frederick W. Reinhardt, "Discharge Characteristics of $\mathrm{Ag}_{2} \mathrm{CrO}_{4}$-Based Cells in $\mathrm{LiNO}_{3}-\mathrm{KNO}_{3}$ Eutectic Electrolyte," $198^{\text {th }}$ Meeting of The Electrochemical Society, Phoenix, AZ, October 22-27, 2000.

8. Ronald A. Guidotti and Frederick W. Reinhardt, "Evaluation of the $\mathrm{Li}(\mathrm{Al}) / \mathrm{MnO}_{2}$ Couple in $\mathrm{LiNO}_{3}-\mathrm{KNO}_{3}$ Eutectic Electrolyte for Borehole Applications," Proc. $41^{\text {st }}$ Power Sources Conf., 141 (2004). 


\section{UNLIMITED DISTRIBUTION}

1 Wright Laboratory

Aero Propulsion and Power

Directorate

Att: D. M. Ryan

WL/POOS-2

1950 Fifth St.

Wright-Paterson AFB, OH

45433-7251

1 Inventek

Attn: T. Kaun

320 Willow St.

New Lenox, IL 60451

2 Army Research Lab

Attn: F. Krieger

A. Goldberg

2800 Powder Mill Road

Adelphi, MD. 20783

1 A. A. Benderly, Consultant 9915 Logan Dr.

Potomac, Maryland 20854

4 Eagle-Picher Technologies, Inc.

Attn: C. Lamb

J. DeGruson

R. Hudson

M. Parrot

P.O. Box 47

Joplin, MO 64802

1 Naval Ordnance Station

Attn: K. Englander

Code 5123C

Indian Head, MD 20640
3 Naval Surface Warfare Center

Attn: C. Winchester

P. Keller

Dr. Patricia Smith

Code 683, Electrochemistry Branch

9500 McArthur Blvd.

W. Bethesda, MD 20817-5700

3 Naval Weapons Center

Attn: R. Nolan (Code 3626)

D. Rosenlof (Code 3626)

Carl Hinners (Code 477400D)

China Lake, CA 93555

3 SAFT America

Attn: K. K. Press

Doug Briscoe

Guy Chagnon

107 Beaver Court

Cockeysville, MD 21030

1 D. Benner

PerkinElmer Optoelectronics

1100 Vanguard Blvd.

Miamisburg, $\mathrm{OH} 45342$

3 Ron Guidotti

Sierra Nevada Consulting

1536 W. High Pointe Ct.

Minden, NV 89423

1 Leclanche, S.A.

Attn: P. Reutschi

48, Avenue de Grandson

CH-1401 Yverdon-Les-Bain

SWITZERLAND

2 ASB

Att: John R. Sweeney

Serge Schoeffert, Research Mgr.

Allée Ste Hélène

18000 BOURGES CEDEX

FRANCE 
1 MS0613 M. R. Prairie, 2520

1 MS0613 D. H. Doughty, 2521

1 MS0613 F. M. Delnick, 2521

1 MS0613 D. Ingersoll, 2521

1 MS0613 K. E. Waldrip, 2521

1 MS0614 T. L. Aselage, 2522

5 MS0614 H. W. Papenguth, 2522

1 MS0614 N. D. Streeter, 2522

1 MS0614 R. G. Jungst, 2523

1 MS0614 L. L. Demo, 2523

1 MS0614 J. A. Gilbert, 2523

1 MS0614 F. P. Lasky, 2523

1 MS0614 L. M. Moya, 2523

1 MS0614 P. C. Butler, 5400

2 MS9018 Central Technical Files, 8944

2 MS0899 Technical Library, 4536 